\title{
Non-invasive Physiological Approaches for Plant Phenotyping: Rice Responses to Heat Stress
}

\author{
Giovani Greigh de Brito ${ }^{1}$, Ítalo Lucas de Moraes ${ }^{2}$, Diogo Silva Moura ${ }^{2}$, Paulo Ricardo Reis Fagundes ${ }^{1}$, \\ Angela Diniz Campos ${ }^{1}$, André Andres ${ }^{1}$, José Maria Barbat Parfit ${ }^{1}$, Luís Eduardo Panozzo ${ }^{3} \&$ Sidnei Deuner $^{2}$ \\ ${ }^{1}$ Empresa Brasileira de Pesquisa Agropecuária, Pelotas, RS, Brazil \\ ${ }^{2}$ Departamento de Botânica, Universidade Federal de Pelotas, Pelotas, RS, Brazil \\ ${ }^{3}$ Departamento de Fitotecnia, Universidade Federal de Pelotas, Pelotas, RS, Brazil \\ Correspondence: Giovani Greigh de Brito, Depto Research and Development, Embrapa Clima Temperado, \\ Pelotas, RS, Brazil. Tel: 55-533-275-8497. E-mail: giovani.brito@embrapa.br
}

Received: November 26, 2018

Accepted: December 28, 2018

Online Published: February 15, 2019

doi:10.5539/jas.v11n3p453

URL: https://doi.org/10.5539/jas.v11n3p453

The research is financed by Brazilian Agricultural Research Corporation (EMBRAPA).

\begin{abstract}
Rice (Oryza sativa L.) can be negatively impacted by supraoptimum temperatures (above $33{ }^{\circ} \mathrm{C}$ ) during initial reproductive phase $\left(\mathrm{R}_{3}-\mathrm{R}_{5}\right)$; development and adoption of approaches via non-invasive physiological phenotyping can lead to help build new plant types to face the current extreme climatic events such as future forecasts. For this purpose, screening process was designed to progressively decrease the genotypes number via non-invasive phenotyping approaches; beyond to allow the increase of phenotyping dimensionality degree across tiers. In a first-tier (in 2015-2016 growth season), phenotyping procedures involved measurements of dossel temperatures via thermography imaging in a set of 182 accessions of subspecies Indica, Japonica and Indica/Japonica cross from Embrapa's Rice Breeding, which were cultivated in two sowing dates. About 30\% (55) of the initial genotypes number which showed the lower canopy temperatures were selected based on results of multivariate analyses. In a second-tier (2016-2017 crop season), a second field trial was conducted, using polythene shelters structures aiming ensure the heat stress imposing during the critical phases of plant development; during this period, an effective photochemical quantum yield of photosystem II (YII) performance was monitored across set of genotypes. Data obtained are highlighted and discussed allowing suggest appointments about the usability/bottlenecks of thermography as suitable tool for phenotyping in a large scale manner; beside highlight the importance of some physiological responses as part of the basis of rice heat tolerance. Concluding, the LTB 14031 and BRS Pampa genotypes outperformed the set of evaluated genotypes across sowing dates and years relative to their physiological and grain yield components variables; these genotypes are integrating cross-breeding aiming to construct new plants ideotype which can associate higher grain yield performance when grown under non-stressed conditions and capable to maintain great yield stability under hard environments.
\end{abstract}

Keywords: stress tolerance, high-temperature, rice breeding, phenomics, physiological phenotyping

\section{Introduction}

The increasingly occurrence of extremes climate events and those forecast to occur yet in the century wave us that our current decisions will determine the size of the climatic impacts on earth life in the next years. Although is unclear the impacts size of these changes on agricultural sustainability, in the current year, the $\mathrm{CO}_{2}$ concentration reached unprecedented registered levels on earth surface (about $403 \mathrm{ppm}$ ) (Olivier et al., 2017). Recently, progress show enhances drying of the Southern Hemisphere and reduces drying of the Northern Hemisphere, increases the formation of Antarctic sea ice (consistent with recent observations of increasing Antarctic sea-ice area) and warms the subsurface ocean around the Antarctic coast (Bronselaer et al., 2018).

In this way, add to challenges associated to feed more than nine billions people in the next decades (Jacquemin et al., 2013; Fan \& Brzeska, 2014), an additional question is related to how supply the food crescent demand by world growth population in face of increasingly uncertainties about climate stability; which could lead to change 
of rain regime, besides of increases in frequency of heat and cold waves as predicted to be increasingly common in next decades. In this sense, abiotic and biotic stresses are the major constraints for agricultural productivity on the global scale and projected climate changes could increase their negative effects in the future (Brito et al., 2010, 2011; Diola et al., 2011, 2013; Weber et al., 2014; Brito et al., 2016b; Guimarães et al., 2017). Beyond of the predict impact of these extreme event on global population remain unclear, its occurrence will probably influence the plant species distributions, productivity, carbon balance and negatively impacting on physiological resilience capacity of plants in a specific environment. Additionally, is important emphasize the stagnation in rice genetic gain for yield in many world regions (Ray et al., 2012). Thus, is imperative to consider that the major challenge is how to overcome this barriers increasing rice production with less land, water, chemicals, and labor; taking into account the need to conserve the environmental and natural resources of degradation. In this way, efforts and new strategies are necessary in the rice breeding programs aiming to define innovative procedures/tools and means to accelerate the construction of new plant types for new economics and climate scenarios. These efforts should include the development and insertion of efficient tools in the rice breeding programs aiming to refining the phenotyping procedures, increase the phenotyping capacity, reduce the involved costs and, consequently, allowing the increase in the number of genotypes to be phenotyped in key steps of the breeding programs.

As has been postulated, a critical bottleneck for accelerating the development of new and superior genotypes is the rapid and accurate phenotypic assessment of thousands of breeding lines, clones or populations over time (Fu, 2015); being these procedures carry out under different environment targets. Thus, there is only a reasonable way to satisfy all these demand, which include the acquisition of high-throughput phenotypic data in some specific breeding stage and define in what breeding phase is possible implement the high-dimensional phenotypic procedures and/or high-resolution. In this sense, significant advances were obtained in the last decades. Nowadays, different platforms are available in different configuration and costs; being used to specific main, such as phenotyping for plants submitted to water deficit, salinity, infra and supra-optimal temperatures, low nutrients, heavy metals and other abiotic stress categories. However, these platforms are generally suitable to functioning under controlled conditions, what can be considered a disadvantage for some applications; besides of the small quantities of genotypes potentially phenotyped per run, when adult plants are used. Reynolds and Langridge (Reynolds \& Langridge, 2016), emphasize that advances in high throughput field phenotyping have boosted the power of physiological breeding. According these authors, almost by definition, high throughput implies use of non-invasive approaches like proximal/remote sensing of spectral reflectance from plant tissue. This approach allow to measure traits which are related to thermal/hydration properties of plant tissues assessed in the infrared region of the electromagnetic spectrum, or pigment profiles estimated in visible bands (Fahlgren et al., 2015). Within this spectral range can be cover canopy temperature, plant water status, photosynthesis performance, nutrient status and some agronomic traits (Reynolds \& Langridge, 2016). However, are still scarce the studies that relate the physiological responses of rice genotypes to heat stress under field conditions; most of studies are carry out under controlled conditions and generally with a small number of genotypes. Additionally, give the potential impact of heat wave on rice grown in the Brazil southern, experiments were conducted aiming the development and validation of a plant phenotyping approach to be used by breeders aiming to identify and select potential genotypes to face the heat waves increasingly frequent in this region.

In this way, whereas great progresses have been made in the cost-efficiency and high-throughput analyses of genetic information as results of "omics" advances, and by increasingly availability of phenotyping platforms able to be used in large-scale, yet exist enormous gaps and bottlenecks which difficult the association of external morphometrics parameters to physiological phenotyping and/or the mechanisms related to plant stress responses. In this sense, efforts should be done by multidisciplinary expertise allowing that complex traits could be broken down into individual components; beyond to be dissected, validated and checked across different scales to become useful as physiological proxy underlying processes used for plants in response to a specific stimulus. However, the vast number of interacting biochemical networks lead to complex physiological hierarchy, which is determinant to define the yield performance in an environment target. Thus, as an alternative aiming to associate yield component variables to physiological performance, a two-tiers approaches involving infra-red imaging acquisition and chlorophyll fluorescence analyzes were done on field trials during two years.

\section{Material and Methods}

\subsection{Experimental Site}

During 2015/2016 and 2016/2017 experiments were carry out at Low-Land Embrapa Experimental Station (LLEES) (31 $\left.{ }^{\circ} 46^{\prime} 19^{\prime \prime} \mathrm{S}, 52^{\circ} 20^{\prime} 33^{\prime \prime} \mathrm{W}\right)$, Pelotas city, in a soil as a Haplic Planossoil (Albaqualf). This trial site is located at $17 \mathrm{~m}$ altitude, a traditional site for rice production under flooding irrigated system situated on 
Brazilian Southern region, using the same field site across years. Before planting, this area was left fallow for five years. Field soil properties were analyzed before the experiments which revealed: organic matter $27 \mathrm{~g} \mathrm{~kg}^{-1}$, available phosphorus $12.5^{-1} \mathrm{mg} \mathrm{kg}$, and available potassium $158.2 \mathrm{mg} \mathrm{kg}^{-1}$; complete chemical soil properties are shown in Table 1.

Table 1. Soil chemical characteristics from $0-20 \mathrm{~cm}$ of the soil profile in lowland Experimental Station (LLES), Embrapa Temperate Climate, Pelotas, RS, Brazil

\begin{tabular}{|c|c|c|c|c|c|c|c|c|c|}
\hline LLES & M.O & $\mathrm{pH}$ & $\mathrm{P}^{(1)}$ & $\mathrm{K}^{+}$ & $\mathrm{Ca}^{2+}$ & $\mathrm{Mg}^{2+}$ & $\mathrm{Al}^{3+}$ & CTC & $\mathrm{V}$ \\
\hline Sample† & $\%$ & water & ------ & $\mathrm{lm}^{3}$ & --- & ------ & $\mathrm{dm}^{3}-$ & ----------- & $\%$ \\
\hline 33096 & 2.7 & 4.8 & 12.5 & 158 & 0.4 & 0.9 & 0.0 & 2.2 & 67 \\
\hline
\end{tabular}

Note. ${ }^{(1)} \mathrm{P}$ was extracted using Mehlich solution and $\mathrm{pH}$ was measured in water. $\uparrow$ Three samples replicates were analyzed.

\subsection{First-tier on 2016-2017 Growth Season: Trial Using Infra-red Image Analysis}

The air temperatures were recorded at each 10 minutes during all cycle; here are shown from anthesis initiate plus 14 days. Air temperatures were monitored and recorded using a Hobbo station with Pendant temp/light (Onset Computer Corporation, Bourne, MA, USA). Hobbo solar radiation shield were installed on central area of experiment and maintained at canopy height to protect the data loggers and sensor of the direct or reflected solar radiation and allowing maximum air flow around the sensor avoiding an overestimate of measured air temperature. Solar radiation data were monitored via a meteorological station located at $300 \mathrm{~m}$ from experimental area via Li-cor sensor integrator (LI-510 Integrator, Li-cor, NE, USA); climatic data are shown in Figure 1.
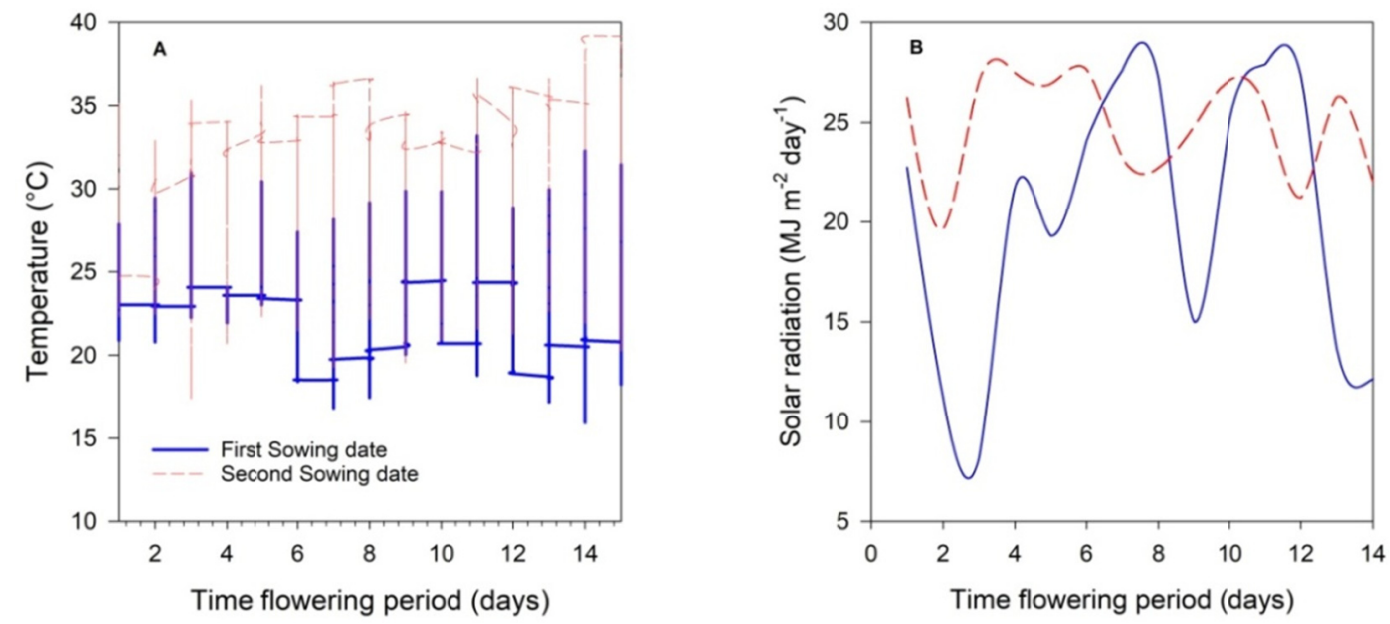

Figure 1. Range of temperatures $\left({ }^{\circ} \mathrm{C}\right)$ recorded during the period of anthesis. Starting at $02^{\text {th }}$ January for first time sowing and starting at $12^{\text {th }}$ Febuary, 2015 for second time sowing (A); solar radiation recorded during the same periods (B)

The conventional soil tillage operations, based on plowing followed by two harrowing, were adopted. Crop management throughout the growing season was carried out according to the Brazilian Official recommendation for rice (SOSBAI, 2014), including fertilizer management. Thus, Starter fertilizer was $15 \mathrm{~kg}$ of N ha ${ }^{-1}, 60 \mathrm{~kg}$ of $\mathrm{P}_{2} \mathrm{O}_{5} \mathrm{ha}^{-1}, 60 \mathrm{~kg}$ of $\mathrm{K}_{2} \mathrm{O} \mathrm{ha}^{-1}$ bank-applied adjacent to each row at planting. The additional nitrogen was $130 \mathrm{~kg}$ of $\mathrm{N} \mathrm{ha}^{-1}$ applied at $\mathrm{V} 4$ growth stage (tillering initiation) and $70 \mathrm{~kg}^{-1} \mathrm{~N} \mathrm{ha}^{-1}$ at $\mathrm{R}_{1}$ growth stage (panicle differentiation) (Counce et al., 2000).

In the first-tier, a set of 182 genotypes from Embrapa's Breeding Program including genetic background of subspecies of Indica, Japonica, and Indica/Japonica cross (Table 3) were used. These rice genotypes were chosen mainly based on their wide adaptability, suitable growth period, and acceptable agronomic aspects as such tillering, stems robustness, leaves morphology, plant height and panicle exertion. 
As a first-tier approach, in 2015-2016 field growth season involved measurement of dossel temperatures via thermography imaging in a set of 182 accessions aiming to identify potential genotypes with superior heat tolerance based on lower dossel temperatures; additionally, investigate the effects of heat stress on yield-components and physiological attributes on different genetic background. In this sense, the first year experiment was conducted at two sowing date; in the first date these genotypes were sowing on October $27^{\text {th }}$, 2015, (best sowing time for rice sowing in Brazilian south region), whereas for second sowing period, the same genotypes were sowed at adjacent area (two meters away) on November $11^{\text {th }}, 2015$ in a split plot in a augmented randomized complete block design (Federer \& Crossa, 2012) with 182 regular treatments with two common treatments (Lemont-stable yield genotype across environment and BRS Querência-a sensitive genotype to thermal oscillation, according previews trials). The experiments were composed by 26 entries in seven blocks, being each plot constituted by four rows spaced at $0.175 \mathrm{~m}$ from each other and measuring $4 \mathrm{~m}$ long, content 40 plants per meter density, approximately. After emergence, ten plants of each cultivar per plot were targeted using a wood cutting to monitor the progress of each phenological phase according to Counce's scale (Counce et al., 2000) and heading phase of each rice genotype was recorded when $50 \%$ panicles emerged from flag-leaf sheath; this procedure was crucial to determine the exact time to do the recommended management and to record eventual occurrence of heat stress events beyond to define the time to start the infra-red imaging acquisitions.

When at least $50 \%$ panicles emerged from flag leaf from latest maturity group (five days of range variation between first and last event occurrence) was made the first imaging acquisition procedure. This procedure was repeated at each seven days during three times. For infra red thermography study, the 650SC thermographic camera (FLIR Systems, Inc., USA) was used, which is sensitive in the mid-wavelength infrared range (MWIR) of 7.5-13 $\mu \mathrm{m}$. This camera is equipped with an uncooled Vanadium Oxide (VOx) microbolometer detector that produces thermal images of $640 \times 480$ pixels. The thermal sensitivity expressed as the noise-equivalent temperature difference (NETD) of the system was $<20 \mathrm{mK}$ at an object temperature of $25^{\circ} \mathrm{C}$. A lens with an angular field of view of $13.1 \mathrm{~mm}\left(45^{\circ}\right)$ was used. The camera was used to take both thermal and RGB visible images automatically in three occasions during anthesis phase for each of the time sowing date. Camera settings for emissivity was calibrated as a constant 0.98 for all measurements. An integrated 3.2-megapixel visual camera for generating visual images was used to merge visual and thermal images to better identify selected parts of leaves during image analysis. All series of measurements were performed at temperatures ranging from $26{ }^{\circ} \mathrm{C}$ to $30{ }^{\circ} \mathrm{C}$ air temperature and relative humidity between $70 \%$ and $80 \%$ in day-light. About forty minutes were the time required to do imaging acquisition off all genotypes. The imaging camera was taken a distance of $1.15 \mathrm{~m}$ from the top canopy plants. Leaves temperature data and background temperature were measured and subsequently recorded in form of radiometric images and analyzed, using FLIR Research IR 4.1 software (FLIR Systems Inc., North Billerica, MA, USA).

\subsection{Second-tier on 2016-2017 Growth Season: Chlorophyll Fluorescence}

After processing and analysis of imaging from first-tier, approximately $30 \%$ of initial genotypes set were selected based on its canopy temperatures. Thus, fifty four genotypes that showed lower canopy temperatures values were chosen to integrate the second-tier of this study. In this way, this genotypes set was sowed during 2016-2017 growth season (October 17, 2016) at adjacent area used before. Thus, a trial was conducted in a split plot on a randomized complete block design with four replicates, being sub plot constituted by three rows spaced at $0.175 \mathrm{~m}$ from each other and measuring $3 \mathrm{~m}$ long, content 40 plants $\mathrm{m}$ density, approximately. The main plots were fifty four genotypes and two temperature levels tested under sub plots. The management practices and fertilization were carryout according to technical recommendations for the crop (SOSBAI 2014) as described before in the first trial year.

As means to ensure the heat stress imposing in the more sensitive phases of the plant development, polythene field-shelters structures were constructed to allow cover all genotypes during stress period $\left(\mathrm{R}_{3}-\mathrm{R}_{5}\right.$ development phase) aiming increase the internal air temperatures whether compared to those cropped on external environment conditions. These structures were compound by 150 micron clear transparent polythene film as commonly used for greenhouses cover and it was sustained by PVC tubes; each shelter constitute of $2.5 \mathrm{~m}$ length, $1.1 \mathrm{~m}$ width and $1.4 \mathrm{~m}$ height, with an opening on the upper surface, as described in Brito and co-authors (Brito et al., 2016a). The mean temperatures into the polythene shelters were about $3{ }^{\circ} \mathrm{C}$ higher than registered in the external environment (Figure 2A) during anthesis phase. Solar radiation was recorded only at external side of the shelters (Figure 2B); internally shelters, there were recorded a decrease of $8 \%$ in solar radiation (data not shown). 

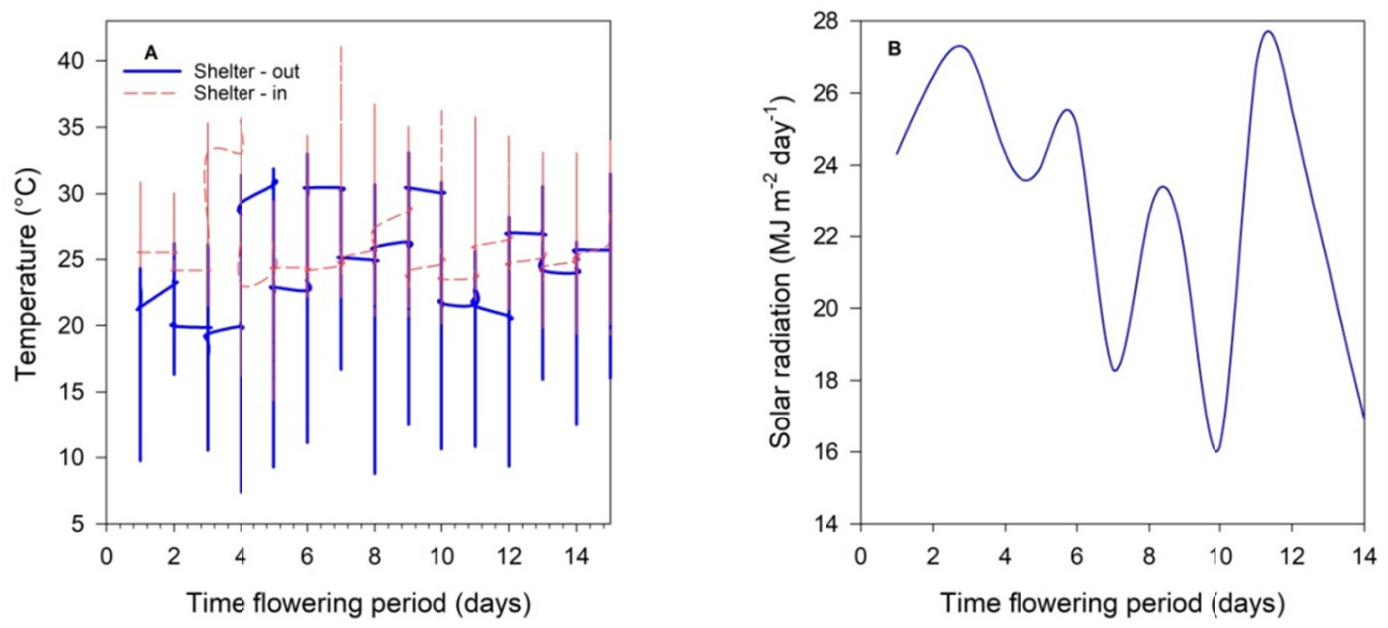

Figure 2. Range of temperatures (A) and solar radiation (B) recorded during the period of anthesis. During this period, the internal solar radiation were only measured at noon, using the a Li-cor sensor Quantum Q45556 coupled to Li-cor $6400 \mathrm{XTR}$; internal solar radiation wasn't significantly decreased, data not shown (B)

In this phase, to investigate the effects of heat stress on some photosynthetic apparatus across genotypes, the effective photochemical quantum yield of PS II (YII) attribute were chosen to be evaluated. YII were chosen considering its feasibility in this genotype number in a short time period. Chlorophyll fluorescence analyzes were done using a PAM-2500 fluorometer (Walz Heinz GmbH, Effeltrich, Germany) equipped with a 2030-B leaf clip holder, which can also monitor PAR and leaf temperature simultaneously. The optic fiber was maintained at a constant distance of $1.2 \mathrm{~cm}$ at an angle of approximately $45^{\circ}$ in relation of the adaxial surface of the leaf during measurement procedures. For measurements, were used flag leaves exposed to ambient light when the photosynthetic apparatus is at full capacity (ambient light readings were taken between 9:00 and 11:00 h a.m). For these procedures the analysis was conducted during day without clouds and with a clear sky, in order to reduce possible sources of variation such as light radiation. During the analysis period, all procedures were conducted at light radiation between 900 and $1100 \mu \mathrm{mol} \mathrm{m}^{-2} \mathrm{~s}^{-1}$. Initially, under these conditions the minimum fluorescence $\left(\mathrm{F}_{0}{ }^{\prime}\right)$ of photosystem II (PSII) centers at partially reduced to the state was determined. The $\mathrm{F}_{0}$ ' correspond to the momentary fluorescence yield $(\mathrm{Ft})$ of an illuminated sample shortly before application of a saturation pulse. Whereas the maximum fluorescence (Fm') at partially closed or in a reduced state of PSII centers was also evaluated after a application of a $0.8 \mathrm{~s}$ pulse of saturating light $\left(7000 \mu \mathrm{mol} \mathrm{m} \mathrm{m}^{-2} \mathrm{~s}^{-1}\right)$. The effective photochemical quantum yield of PSII (YII) was defined as (Fm' - F)/Fm'. Summarizing, Fm' parameter was quantified in plants subjected to light-adapted state via application of a saturating pulse, whereas $\mathrm{F}_{0}$ ' was evaluated by switching off the actinic light for two seconds after the saturating pulse and turned on the far-red light. The electron transport rate (ETR) was calculate as PAR.ETR-factor.PPS2/PPPS.Y(II) (Baker, 2008) (Data not shown).

\subsection{Yield Components Quantification}

At physiological maturity, yield per square meter was quantified harvesting the two lines of each plot, excluding the $50 \mathrm{~cm}$ extremities of the lines. The grain weight was adjusted to $14 \%$ moisture content. Yield components were measured via panicle grain number determination, spikelet sterility and 1000-grain weight.

\subsection{Statistical Analysis}

For the first-tier of this study, multivariate analyzes, via principal component analysis (PCA) were performed to identify heat tolerance relationship among genotypes. In addition, a step-by-step PCA procedure was performed to identify genotypes potentially tolerant to supraoptimum temperatures and, at same time, excluding redundant evaluated parameters. These PCA step-by-step procedures allowed us progressively exclude redundant morphometrics and physiological variables with equal contributions (overlapping). Subsequently, for second-tier of this study, data from those selected genotypes for each evaluated parameters were subjected to ANOVA procedures aiming to test existence of the statistic significant interaction between the different ambient temperatures and genotypes; when statistically significance was detected, unfold statistical procedures were done to quantify the effects of each genetic background within each temperatures regime. Subsequently, the Least 
Significant Difference (LSD) among the means was statistically analyzed using Student-Newman-Keuls test $(\mathrm{p}<$ 0.05). The SigmaPlot version 13 (Systat Software Inc., San Jose, CA, USA) software was used for analyzes.

\section{Results}

Aiming to develop and validate a suitable phenotyping approach for rice breeding, this study involved the adoption of thermal imaging and analysis of chlorophyll fluorescence procedures across a large set of rice genotypes; carry out during growth seasons and years. At first-tier, the acquisition and analysis of thermographic images led to identify genotypes that outperformed for low leaves temperatures across seasons; besides highlighted significant correlations between leaves temperatures and grain yield. Initially, a PCA analysis was performed using all physiological variables under investigation; verified that two principal components (PCs) (Figure 3) were significant. For first sowing date, PC1 and PC2 contributed to variations of 30.02 and 23.95, respectively. Whereas, at second sowing date, the same genotypes showed sequentially, significant PCs values of 39.84 and 30.88, respectively. PCs indicated that the two important components accounted for about 54 and 70 percent of the total variation, among evaluated traits in the set of rice genotypes for first and second time sowing, respectively. The first component assigned 30.02 and 39.84 percent of total variation between traits for first and second time sowing, respectively; besides, there were significantly related with grain yield (Figures 3A and 3B).
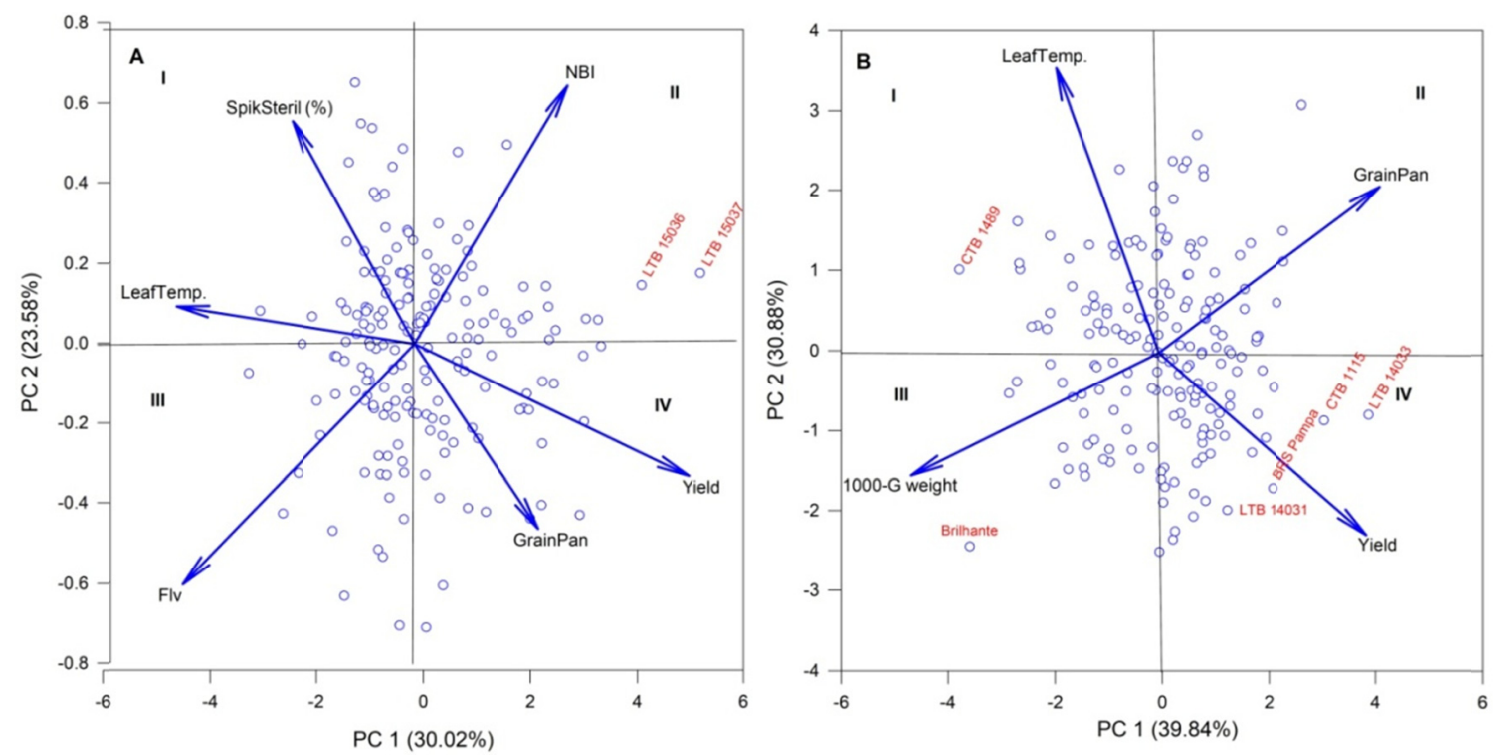

Figure 3. Principal component analysis for the first (A) and second sowing date (B). Individual contribution of each parameter measured as such LeafTemp (leaf temperatures - ${ }^{\circ}$ C), GrainPain (Grain per panicle — grain number per panicle), NBI (nitrogen balance index), Flv (Flavonoids index), SpikSteril (Spikelet sterility—\%),

1000-G weight (1000-grain weight—g) and Grain Yield (grain yield — g per square meter). The two first components display 53.60 and $70.72 .67 \%$ of the total phenotypic variance for first and second time sowing, respectively. The component loading vectors (represented in lines) of each variable (traits evaluated) were superimposed proportionally to their contribution. Empty circles symbolize the set of evaluated genotypes

In this sense, the highly variability shown by these evaluated components suggest the possibilities of selection of genotypes from these PCs reported here. Additionally, there was a highly negative correlation between grain yield and leaf temperatures, showing that genotypes with high leaf temperatures had a significant decrease in its grain yield on the first time sowing. At this sowing date, the LTB 15036 and LTB 15037 genotypes showed highest values for nitrogen content via NBI (Nitrogen balance index) a physiological variable and for grain yield, as shown by second quadrant of Figure 3A. Whereas, for second sowing date, the CTB 1115 and LTB 14033 were closely related to higher grain yield and lower leaf temperatures, as highlighted by quadrant four in Figure 3B. On the other hand, Brilhante genotype, in the quadrant III, showed lowest grain yield (Figure 3B), while maintained the highest chlorophyll content (data not shown). For second time sowing, plants were submitted to heat stress at least for short time during the flowering phase. At this environment condition, those genotypes showing higher and lower grain yield, also had the lower and higher leaves temperatures, respectively. Spearman rank order correlation showed a significant negative correlation between leaf temperature and yield per square 
meter $(\mathrm{r}>-0.37, \mathrm{P}<0.01)$ for those plants cropped at first sowing date and a moderate correlations values $(\mathrm{r}>$ $-0.4, \mathrm{P}<0.01$ ) for those sowed in second sowing date (data not shown). However, the association between these two variables is not very strong; thus, future studies should include changes in the plot size, experimental design and time duration to image acquirements aiming to improve the correlation values, allowing use them as a strong predictor for genotype selection. On the other hand, there were non-significant correlations for other evaluated physiological parameters and quantified yield-components (data not shown).

For second time sowing, where the historical risk of heat wave occurrence is higher, CTB 1489 genotype recorded $28.9{ }^{\circ} \mathrm{C}$ of leaves temperature; this genotype showed low grain yield values $(2,480$ kilograms per hectare) as highlighted by quadrant one of PCA analysis (Figure 3B). By other side, LTB 14033 and BRS Pampa showed lower leaves temperatures, $27.3{ }^{\circ} \mathrm{C}$ and $27.2^{\circ} \mathrm{C}$, respectively. These genotypes showed the highest grain yield performance, (11,000 kg per hectare, approximately); its can be located at fourth quadrant of PCA analysis. Together, these two variables explain more than fifth percent of existent variability in the data set analyzed. Additionally, is important to emphasize that leaves temperatures measured via infra-red images was significantly and negatively correlated with grain yield $(\mathrm{r}=-0.40 ; \mathrm{P} \leq 0.001)$ for this sowing date, highlighting its suitability as tool to identify genotypes with high grain yield potential in a breeding program.

The use of heat stress index adapted from Fischer and Maurer (1978) indicate that some genotypes were superior for heat tolerance based on the index values (Figures $4 \mathrm{~A}$ and $4 \mathrm{~B}$ ); taking into account its stability reactions across two time sowing date; 30 genotypes were classified as highly heat tolerant which showed lower values index $($ HTI $\leq 0.5)$; specifically LTB 14035, LTB 13023, BRS-7 Taim, BRA 050151 and LTB 15047 which showed values below 0.1 (Figure 4A); 30 genotypes were classified as moderately tolerant based in its threshold values $(0.5 \leq 1)$ (Figure 4B); besides, 119 genotypes had HTI higher than 1.0 and, therefore, were classified as sensitive genotypes (data not shown).
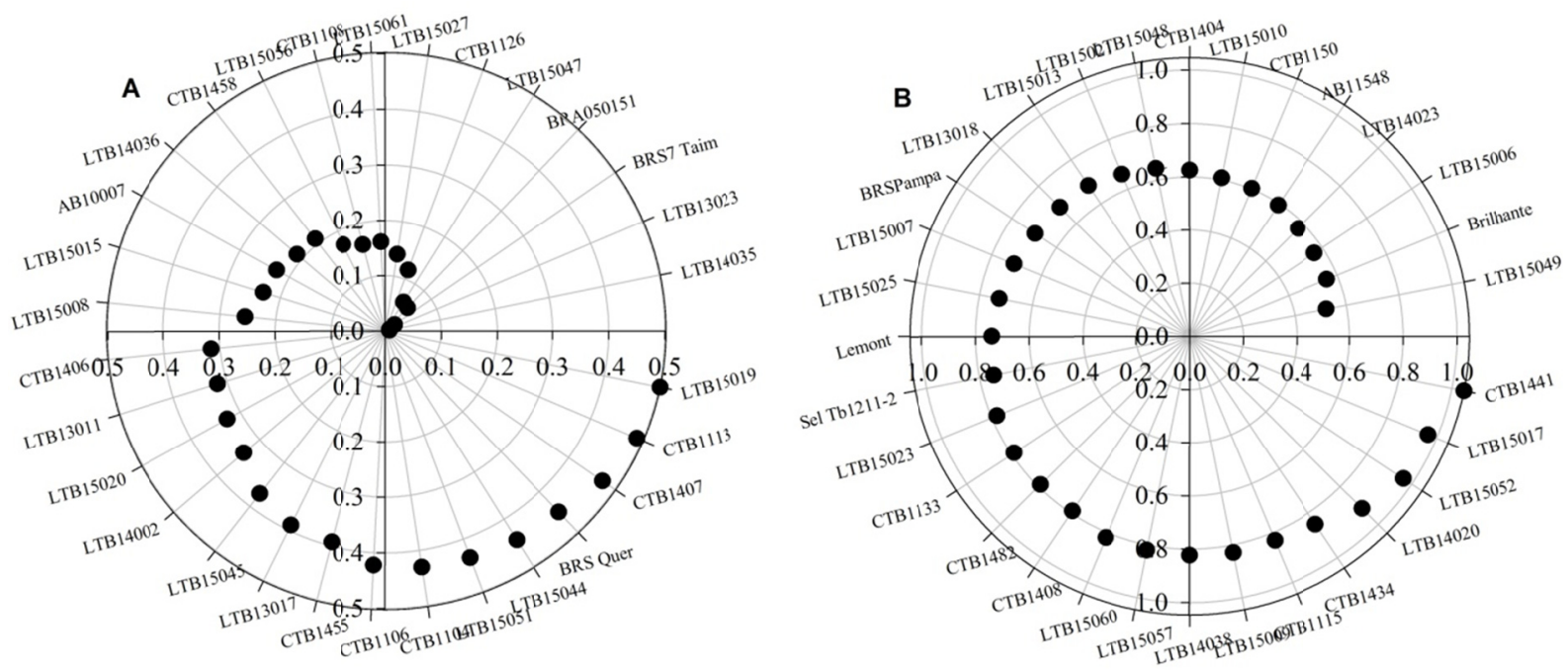

Figure 4. Fischer and Maurer index for the high $(<0.5-\mathrm{A})$ and median $(0.5-1.0-\mathrm{B})$ stress tolerance, based on the grain yield average of the two sowing dates

As results of this first-tier study, at first time sowing the maximum absolute temperature was record at eleven days after anthesis initiate $\left(33.01{ }^{\circ} \mathrm{C}\right)$ whereas for second sowing date, at this time the absolute values reached $36.5^{\circ} \mathrm{C}$ highlighting a more hard environment condition during this sensitive phase. Additionally, for second sowing time there were supra-optimal temperature $\left(>33^{\circ} \mathrm{C}\right)$ occurrence during six days after anthesis initiation, sequentially. In general, the occurrence of the contrasting air temperatures during the most sensitive phase increased the spikelet sterility (8\%), decreasing grain per panicle $(9 \%)$ and the grain yield $(12 \%)$ across set of genotypes; on the other hand, there were no significant differences in 1000-grain weight (data not shown). These data highlight the direct impact of supra-optimal temperatures on events as anther dehiscence, pollination and pollen germination, which can leads to spikelet sterility and, consequently, grain yield loss (Yoshida 1981b) (Yoshida, 1981). As emphasized by Jagadish et al. (2007), increases in spikelet sterility has been recorded even when sensitive genotypes are submitted to supra-optimal temperatures by less than an hour. 
Subsequently, a summary of the ANOVA of the parameters evaluated in this research is shown in Table 2; where are shown a significant interaction for the photochemical quantum yield of PS II, besides genotypes and temperatures regime effects.

Table 2. Summary of the ANOVA from evaluated parameters in 55 rice genotypes submitted to continuous flooding and severe alternate wetting and drying management

\begin{tabular}{lll}
\hline \multirow{2}{*}{ Source of variation } & \multicolumn{2}{c}{ Mean square } \\
\cline { 2 - 3 } & Degree of Freedom & Y (II) \\
\hline Genotypes $(\mathrm{G})$ & 54 & 0.0323 \\
Temperatures regime (TR) & 1 & 0.0221 \\
$\mathrm{G} \times \mathrm{TR}$ & 54 & 0.0180 \\
Error & 550 & 0.0051 \\
\hline
\end{tabular}

Note. Y (II): photochemical quantum yield of PS II; * significant at $\mathrm{p}<0.05, * *$ significant at $\mathrm{p}<0.01$ by the F-test. ${ }^{\text {ns }}$ not significant at a threshold probability, by the F-test.

As shown by ANOVA, at second-tier of this study, were investigated the effects of heat stress on performance of an important functioning component of the photosynthetic apparatus across set genotypes. The measurements of the effective photochemical quantum yield of PS II (YII) attribute allowed us a fast analysis of photosynthetic status of a specific genotype when submitted to heat stress (Figure 5).
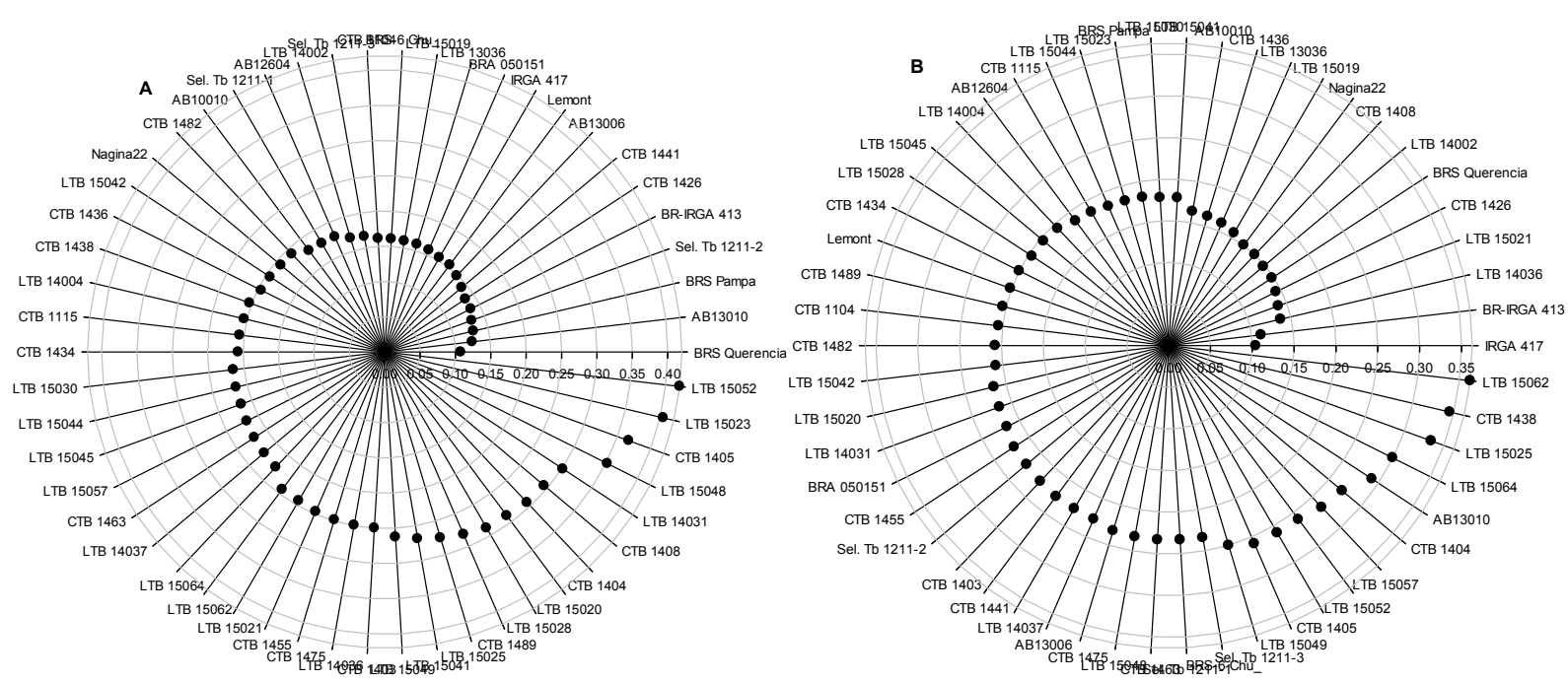

Figure 5. Effective photochemical quantum yield of PS II-Y(II) of set of 55 genotypes cropped under field conditions (external shelters) (A) and subjected to heat stress during anthesis (internal shelters) (B). Each point in the graphic is a mean of eighteen replicates $(n=18)$; being the mean of the six replicates per three measurements dates

In general, Y (II) of stressed flag leaves were significantly declined when compared to those maintained under external temperatures conditions (Figure 5B). However, some genotypes were stable across the environments, such as CTB 1404. By other side, the LTB 15062 which showed the highest Y (II) under stressed condition lowered its stability across evaluated environments; outperforming in $73 \%$ the mean of evaluated set genotypes.

\section{Discussion}

According to the historic weather data and taking into account the years from 1971-2000 (http://agromet.cpact. embrapa.br/estacao/mensal.html), the hottest period at Low-Land Embrapa Experimental Station (LLEES) is from mid-January to the end of February. Historic weather data highlight an increase in the frequency of absolute maximum temperature threshold (higher than $33^{\circ} \mathrm{C}$ ), during the hottest months (January up to February), which are above the optimal threshold for rice flowering events (Yoshida, 1981). For this reason, the first sowing date 
was adjusted to allow the rice genotypes to flower in a favorable condition, below the heat stress threshold, whereas the second sowing period would increase the probability of the rice genotypes to have high temperatures during their reproductive phase (mid- February to the end February).

For rice early development, which involve an adequate germination and seedling establishment, this specie requires temperatures situated between 20 and $35{ }^{\circ} \mathrm{C}$ (Yoshida, 1981a). By other side, during initial reproductive phases such as booting and flowering phases optimum temperatures should be situated between $25-28{ }^{\circ} \mathrm{C}$ and $30-32{ }^{\circ} \mathrm{C}$, respectively (Yoshida, 1981). During these phases, infra and supra-optimal temperatures has been affected the anther dehiscence, pollination and pollen germination, increasing spikelet sterility and consequently leading to yield reduction of rice grains (Brito et al., 2016; Jagadish et al., 2007; Yoshida, 1981). According to these authors, when subjected to supra-optimal temperatures, even for a short time (less than one hour), its negative effects can lead in the increase of rice spikelet sterility and, consequently, decreasing grain productivity.

Despite the rice susceptibility to supra-optimum temperatures during its reproductive phase, rice germplasm (Indica and Japonica) exhibiting wide genetic variability for heat-stress tolerance is available and can be exploited to develop rice varieties with improved tolerance to heat-stress. Even though considering that Indica ssp accessions are more tolerant to this specific stress, the increased use of Japonica ssp in rice breeding programs around world has allowed the insertion and recombination of valorous alleles, which needs to be identified, dissected and used to accelerate the breeding processes aiming to develop cultivars with improved tolerance to supraoptimum temperatures (Moura et al., 2017, 2018a, 2018b).

Taking into account the first-tier of this study, when a high genotype number were phenotyped, the PCA analysis highlight the amplification of information obtained from classic tests, highlighting links between phenotypic variables and genotypes in a more convenient way; in addition, PCA helped to group genotypes because to its ability to minimize higher number of variables into fewer components, but the key feature of PCA is the fact that it makes possible to clear the different responses followed by each genotypes facing heat-wave stress. In our report, PCA analysis made for first and second time sowing showed a significant and negative correlation between leaves temperatures and grain yield, highlighting the powerful of this relationship, where the increase of leaves temperature leads to a decrease in grain yield. Although many studies have found significant correlations between leaves or canopy temperatures and stomatal conductance, unfortunately, only a few examples has shown its association with yield components variables. However, the use of remote sensing via thermo-image, as adopted in this report, has gained increasingly use with technological advances and available devices. Infrared thermography have been proposed as useful tools for monitoring crops for their tolerance to high temperature stresses (Janka et al., 2013) and other stress sources. Thus, canopy temperature has been proposed as a proxy to plant phenotyping procedures for heat tolerance in wheat; highlighting that those plants with lower canopy temperature are more tolerant to this stress factor than those genotypes with higher canopy temperatures (Pinto et al., 2010). Taken into account the high capacity of some genotype to decrease its leaves temperatures via evaporation event, what leads a direct relationship between leaf temperatures, transpiration rate, stomatal conductance and $\mathrm{CO}_{2}$ assimilate rates, the adoption of this approach by breeders could allow them select those plants with better physiological potential performance in response to heat stress during critical development phase of the crop. In this sense, this approach will allow the breeders to associate external phenotypic traits to physiological responses, what can lead increasingly accurate, intensity of selection, uncover of variability and, consequently increase the genetic gain into the breeding program.

When the Fischer and Maurer index (FMI) (Fischer \& Maurer, 1978) were applied, from 182 genotypes, just $16.48 \%$ were considered as highly tolerant, $16.48 \%$ as moderately tolerant and $65.38 \%$ as sensitive. The CTB 1406 e CTB 1407 genotypes highlighted high tolerance to heat stress with FMI of 0.31 and 0.45 , respectively, considering the Fischer and Maurer index. On the other hand, these genotypes showed grain yield values likely the means showed by set of evaluated genotypes. Even though, will be necessary consider that an efficient index suitable marker for heat-tolerance selection, should be able to discriminate multiple genotypes besides allow us select those with high grain yield performance combined with heat tolerance. By other side, has been noticed that selection using this index can favors genotypes with low yield performance when plants are grown under non-stressed conditions; such as was found by our study. Thus, the use of this index for heat tolerance selection can show disadvantages for some situations, such as specific environment target; where the frequency of heat-wave occurrence is low. In this sense, if consider our uncertainties about the frequency and intensity of heat-wave occurrence in Brazilian rice production areas, the use of this index cannot be a better option for use by breeders. Thus, Brazilian rice breeding program needs to establish selection criteria that allow us select genotypes more tolerant to heat stress and at same time that show great performance when grown under non-stressed conditions, likely shown here by infra red thermography approach. 
The anthesis sub-period is the most sensitive to supra-optimal temperatures (above $33^{\circ} \mathrm{C}$ ) (Tenorio et al., 2013). As highlighted by other studies, the occurrence of supra-optimal temperatures during this phase may increase the spikelet sterility, as result of the decrease in the anther dehiscence, pollination and pollen germination, which lead to a decrease of the grain yield (Brito et al., 2016; Jagadish et al., 2007; Yoshida, 1981). Our data highlight that different mechanisms should be involved in the high-grain yield performance when plants are submitted to heat stress, whether consider that not always genotypes highlighted lower leaves temperatures at first-tier, were those that also showed better performance for Y (II) at second-tier of the study. In general, genotypes showing higher Y (II) were not associated with higher grain yield. On the other hand, genotypes which highlighted lower leaves temperatures associated with higher grain yield in the first-tier were also those maintained great grain yields on the second-tier of this study. This tendency highlights the potential use of thermal image as a surrogate for physiological phenotyping, where will be possible select genotypes with high grain yield associating them with higher leaves cooling capacity. In the same accessions, the efforts were concentrate to investigate the association between canopy temperature across multiples genotypes with some physiological and yield-component aiming establish a phenotyping procedure suitable to be used by rice breeders aiming large-scale phenotyping for heat stress tolerance; beside, identification of genotypes that could be used for future genetic studies and/or as parents for our breeding program.

In this context, leaf temperatures which are closely related to gas exchange performance (Jossier et al. 2010), could be useful as a proxy to estimating stomatal conductance rate when plants are submitted to heat stress (Katul et al., 2000). Even though considering that there were found significant correlations for these variables, we believe that will be need some adjustment in the imaging acquisition procedures, aiming reduce the required time for this procedure leading to avoid/decrease the effects of fast environment changes, such as light, cloudiness, temperature and vapor pressure deficit which can increase the interferers on data set; in this sense, for the next step of this study we intend to take care with the adopted image procedures, aiming increase the correlations values found in this report. As alternative to reduce interferes, efforts can be made to design experiments with small plots and blocks arranged to allow reducing the number of image required per block and, consequently, decreasing the time required for imaging procedures.

Finally, even though great advances in sensors and devices technologies for plant phenotyping in large-scale are increasingly available, still there are limitations to associate external phenotypes obtained from a image approach to a physiological trait that contribute decisively for those performance. Thus, in breeding program where thousands of genotypes need to be phenotyped, strong efforts should be put in the development and validation of robust and non-expensive methodologies capable to be useful in a breeding program routine, considering the need to be associated to some heritability and related to some component of the agronomic interest. There are some bottlenecks that need to be considered, which are interferers decreasing the reliability of generated data. For adequate adoption of thermography, some key precautions should be taken to account to provide a reliable high-throughput phenotyping tool, especially on the need to consider the variations resulting from fast environmental changes, which include fast changes in the incident radiation, wind speed, vapor pressure deficit, etc. Besides the importance of use of normalization techniques to reduce the associated errors generated during data acquisition procedures. Concluding, the LTB 14031 and BRS Pampa genotypes outperformed the set of evaluated genotypes across sowing dates and years, relative to their physiological and grain yield components variables; these genotypes are integrating cross-breeding aiming to construct new plant ideotype which can associate higher yield performance when grown under non-stressed conditions and capable to maintain great yield stability under hard environments.

\section{References}

Bahuguna, R. N., Solis, C. A., Shi, W., \& Jagadish, K. S. (2017). Post-flowering night respiration and altered sink activity account for high night temperature-induced grain yield and quality loss in rice (Oryza sativa L.). Physiologia Plantarum, 159(1), 59-73. https://doi.org/10.1111/ppl.12485

Baker, N. R. (2008). Chlorophyll fluorescence: a probe of photosynthesis in vivo. Annu Rev Plant Biol, 59, 89-113. https://doi.org/10.1146/annurev.arplant.59.032607.092759

Brito, G. G., Caixeta, E. T., Gallina, A. P., Zambolim, E. M., Zambolim, L., Diola, V., \& Loureiro, M. E. (2010). Inheritance of coffee leaf rust resistance and identification of AFLP markers linked to the resistance gene. Euphytica, 173(2), 255-264. https://doi.org/10.1007/s10681-010-0119-x

Brito, G. G., Fagundes, P. R. R., Teló, G. M., Abreu, A. G., \& Magalhães Júnior, A. M. (2016a). Impact of supra-optimal temperatures on physiology and yield in rice field. Journal of Agricultural Science, 8(2), 27-37. 
Brito, G. G., Sofiatti, V., Lima, M. M. A., Carvalho, L. P., \& Silva-Filho, J. L. (2011). Physiological traits for drought phenotyping in cotton. Acta Scientiarum Agronomy, 33(01), 117-125. https://oi.org/10.4025/ actasciagron.v33i1.9839

Bronselaer, B., Winton, M., Griffies, S. M., Hurlin, W. J., Rodgers, K. B., Sergienko, O. V., ... Russell, J. L. (2018). Change in future climate due to Antarctic meltwater. Nature. https://doi.org/10.1038/s41586-018 $-0712-\mathrm{z}$

Counce, P. A., Keisling, T. C., \& Mitchell, A. J. (2000). A uniform, objective, and adaptative system for expressing rice development. Crop Science, 40, 436-443. https://doi.org/10.2135/cropsci2000.402436x

Diola, V., Brito, G. G., Caixeta, E. T., Pereira, L. F. P., \& Loureiro, M. E. (2013). A new set of differentially expressed signaling genes is early expressed in coffee leaf rust race II incompatible interaction. Funct Integr Genomic, 13(3), 379-389. https://doi.org/10.1007/s10142-013-0330-7

Diola, V., de Brito, G. G., Caixeta, E. T., Maciel-Zambolim, E., Sakiyama, N. S., \& Loureiro, M. E. (2011). High-density genetic mapping for coffee leaf rust resistance. Tree Genet Genomes, 7(6), 1199-1208. https://doi.org/10.1007/s11295-011-0406-2

Fahlgren, N., Gehan, M. A., \& Baxter, I. (2015). Lights, camera, action: High-throughput plant phenotyping is ready for a close-up. Curr Opin Plant Biol, 24, 93-9. https://doi.org/10.1016/j.pbi.2015.02.006

Fan, S., \& Brzeska, J. (2014). Feeding More People on an Increasingly Fragile Planet: China's Food and Nutrition Security in a National and Global Context. Journal of Integrative Agriculture, 13(6) 1193-1205. https://doi.org/10.1016/S2095-3119(14)60753-X

Fu, Y. B. (2015). Understanding crop genetic diversity under modern plant breeding. Theor Appl Genet, 128(11), 2131-42. https://doi.org/10.1007/s00122-015-2585-y

Guimarães, C. M., Stone, L. F., Brito, G. G. D., \& Heuert, J. (2017). Evaluation of water-stress tolerance of Acala SJ 2 and Auburn 2 cotton cultivars in a phenotyping platform. Revista Ambiente \& Água, 12, 629-642. https://doi.org/10.4136/ambi-agua.2105

Jacquemin, J., Bhatia, D., Singh, K., \& Wing, R. A. (2013). The International Oryza Map Alignment Project: development of a genus-wide comparative genomics platform to help solve the 9 billion-people question. Curr Opin Plant Biol, 16(2), 147-156. https://doi.org/10.1016/j.pbi.2013.02.014

Jossier, M., Kroniewicz, L., Dalmas, F., Le Thiec, D., Ephritikhine, G., Thomine, S., ... Leonhardt, N. (2010). The Arabidopsis vacuolar anion transporter, AtCLCc, is involved in the regulation of stomatal movements and contributes to salt tolerance. The Plant, 64, 563-576. https://doi.org/10.1111/j.1365-313X.2010.04352.x

Moura D. S., Brito G. G., Campos A. D., Moraes I. L., Porto G. S. F., Teixeira S. B., ... Deuner S. (2017). Non-structural carbohydrates accumulation in contrasting rice genotypes subjected to high night temperatures. Journal of Agricultural Science, 9(12), 302-315. https://doi.org/10. 5539/jas.v9n12p302

Moura, D. S., Brito, G. G., Fagundes, P. R., \& Castro, A. (2018a). Cold tolerance in rice plants: Phenotyping procedures for physiological breeding. Journal of Agricultural Science, 10(1), 313-324.

Moura, D. S., Moraes, I. L., Armensto, R. S., Silva, R. S., Reolon, F., Borela, J., ... Deuner, S. (2018b). Above-optimum temperature-induced differential photosynthetic and roots morphometric responses in two contrasting rice genotypes. Journal of Agricultural Science and Technology, 7, 309-319.

Olivier, J. G. J., Schure, K. M., \& Peters, J. A. H. W. (2017). Trends in global $\mathrm{CO}_{2}$ and total greenhouse gas emissions (Vol. 2983). PABLO Publishers Netherlands Environmental Assessment Agency, Netherlands.

Ray, D. K., Ramankutty, N., Mueller, N. D., West, P. C., \& Foley, J. A. (2012). Recent patterns of crop yield growth and stagnation. Nature Communications, 3, 1293. https://doi.org/10.1038/ncomms2296

Reynolds, M., \& Langridge, P. (2016). Physiological breeding. Current Opinion in Plant Biology, 31, $162-171$. https://doi.org/10.1016/j.pbi.2016.04.005

Weber, R. L., Wiebke-Strohm, B., Bredemeier, C., Margis-Pinheiro, M., de Brito, G. G, Rechenmacher, C, ... Bodanese-Zanettini, M. H. (2014). Expression of an osmotin-like protein from Solanum nigrum confers drought tolerance in transgenic soybean. BMC Plant Biol, 14, 343. https://doi.org/10.1186/s12870-0140343-y

Yoshida, S. (1981a). Fundamentals of rice crop science. Los Baños: IRRI. 


\section{Copyrights}

Copyright for this article is retained by the author(s), with first publication rights granted to the journal.

This is an open-access article distributed under the terms and conditions of the Creative Commons Attribution license (http://creativecommons.org/licenses/by/4.0/). 